\title{
Iranian nurses' perceptions about using physical restraint for hospitalized elderly people: a cross-sectional descriptive- correlational study
}

Azam Sharifi ${ }^{1}$, Narges Arsalani ${ }^{1 *}$, Masoud Fallahi-Khoshknab ${ }^{1}$, Farahnaz Mohammadi-Shahbolaghi ${ }^{1}$ and Abbas Ebadi ${ }^{2,3}$

\begin{abstract}
Background: Using physical restraint (PR) for hospitalized elderly people is a major nursing challenge. It is associated with different physical and mental complications and ethical dilemmas, though many nurses still use it to ensure patient safety. Nurses' perceptions are one of the most important factors affecting PR use. This study aimed to evaluate Iranian nurses' perceptions about PR use for hospitalized elderly people.

Methods: This cross-sectional descriptive-correlational study was conducted from July to December 2019. Participants were 270 hospital nurses who were purposively recruited from intensive care units and medical and surgical wards of three teaching hospitals in Kermanshah, Iran. Data were collected using a demographic questionnaire and the Perceptions of Restraint Use Questionnaire (PRUQ). The SPSS software (v. 23.0) was used for data analysis through the independent-sample $t$ test, the one-way analysis of variance, and the multiple regression analysis.

Results: The total mean score of PRUQ was $4.08 \pm 0.12$ in the possible range of $1-5$. The most important reasons for PR use were to prevent patients from falling out of bed and to prevent them from pulling out catheters. The total mean score of PRUQ had significant relationship with participants' age, work experience, and history of receiving PR-related educations $(P<0.05)$, but had no significant relationship with their gender, educational degree, and affiliated hospital ward $(P>0.05)$.

Conclusion: This study suggests that nurses attach high importance to PR use for hospitalized elderly people. Healthcare policy-makers at national and hospital levels are recommended to provide nurses with PR-related educations in order to reduce the rate of PR-related complications.
\end{abstract}

Keywords: Physical restraint, Nurse, Elderly, Hospital

\footnotetext{
*Correspondence: n.arsalani@yahoo.com

${ }^{1}$ Nursing Department, University of Social Welfare and Rehabilitation Sciences, Tehran, Iran

Full list of author information is available at the end of the article
}

(C) The Author(s). 2020 Open Access This article is licensed under a Creative Commons Attribution 4.0 International License, which permits use, sharing, adaptation, distribution and reproduction in any medium or format, as long as you give appropriate credit to the original author(s) and the source, provide a link to the Creative Commons licence, and indicate if changes were made. The images or other third party material in this article are included in the article's Creative Commons licence, unless indicated otherwise in a credit line to the material. If material is not included in the article's Creative Commons licence and your intended use is not permitted by statutory regulation or exceeds the permitted use, you will need to obtain permission directly from the copyright holder. To view a copy of this licence, visit http://creativecommons.org/licenses/by/4.0/ The Creative Commons Public Domain Dedication waiver (http://creativecommons.org/publicdomain/zero/1.0/) applies to the data made available in this article, unless otherwise stated in a credit line to the data. 


\section{Background}

Patient safety is a main component of healthcare quality [1]. Ensuring patient safety is among the basic rights of patients and one of the main goals of nursing care [2, 3].

Restraint is one of the methods for ensuring patient safety [4-6]. Restraint refers to any medication or device used to restrict patients' voluntary movements in order to prevent injuries to patients and others [7, 8]. There are two main types of restraint, namely chemical and physical. Chemical restraint is to calm patients, lower the level of their consciousness, and reduce their responsiveness to environmental stimuli through sedative agents. In chemical restraint, sedative agents (including opioids, benzodiazepines, and muscle relaxants) are used to induce tranquility and pain relief, reduce intracranial pressure, and prevent the accidental removal of catheters [8-10]. Physical restraint (PR) refers to "any action or procedure that prevents a person's free body movement to a position of choice and/or normal access to his/her body by the use of any method, attached or adjacent to a person's body that he/she cannot control or remove easily" [11]. PR devices include wrist, ankle, chest, and waist restraints and bed rails $[6,11]$.

The prevalence of PR use among hospitalized patients is $10-75 \%$ [12-15]. This prevalence is three times greater among elderly people $[16,17]$. This high prevalence may be related to the high hospitalization rate among elderly people secondary to their affliction by different chronic conditions $[18,19]$. Hospitalization of elderly people is associated with different adverse events and safety issues because most of them have poor health status, use multiple medications, may suffer from cognitive or functional disorders, and hence, are at risk for fall and injury to self or others [17, 20-22]. Therefore, nurses often use PR to restrict their movements and ensure their safety [23, 24].

Nurses have many reasons for PR use. These reasons include ensuring patient safety, preventing treatment discontinuation, preventing patient fall, controlling agitated or restless patients, protecting patients and others against injuries, creating a safe environment, and overcoming the problems associated with staff shortage $[3,4,6]$.

Although PR is used to ensure patient safety, there is limited evidence concerning its effectiveness [25]. Studies show that PR can endanger patient safety and cause different physical and mental complications. Physical complications include pressure ulcer, contracture, physical and cognitive dysfunction, prolonged hospital stay, increased likelihood of patient fall, asphyxia, and death due to strangulation [14, 26-28]. PR-associated mental complications include anger, frustration, aggression, fear, anxiety, depression, and reduced self-confidence [2932]. Besides, PR use is associated with ethical dilemmas because it contradicts patients' right to have autonomy and may negatively affect their dignity [33, 34]. PR use for hospitalized elderly people can also delay recovery $[5,19,35]$.

Nurses have significant role in decision making about PR use [3, 4, 36-40]. One of the factors which may require nurses to use PR is their perceptions about PR use $[2,24,41,42]$. Studies showed that nurses' decision about PR use is greatly affected by their perceptions [3, 6 , 41-43]. A mixed-method study also showed that a sense of security, heavy workload, and staff shortage can affect nurses' perceptions about PR use [6]. Other factors affecting nurses' perceptions about PR use include patients' characteristics, nurses' knowledge and attitudes, cultural factors, and professional regulations $[4,6,31$, $35,44-46]$. There are strict regulations on PR use in some countries [4, 20,31, 42]; however, there is no clear guideline for PR use in healthcare settings in Iran.

Some studies showed that despite the wide use of PR, nurses have limited knowledge about appropriate PR use [40, 47].

Although different studies evaluated nurses' perceptions about PR use in different countries [2, 6, 24, 31, $41,42]$, there are limited data, if any, about Iranian nurses' perceptions about PR use. The present study was conducted to address this gap. The aim of the study was to evaluate nurses' perceptions about PR use for hospitalized elderly people. Understanding these perceptions can form a basis for developing and using interventions to reduce PR use.

\section{Methods}

This cross-sectional descriptive-correlational study was conducted from July to December 2019 in three teaching hospitals in Kermanshah, Iran. Kermanshah is a large city in the west of Iran with three general teaching hospitals and several specialty teaching hospitals (including cardiac, psychiatric, maternity, and children's hospitals). Study setting was the three general teaching hospitals in the city and study population consisted of all 688 nurses who worked in these hospitals. Using the Cochran formula and with a confidence level of $95 \%$ and a $d$ of 0.05 , sample size was calculated to be 246 . Yet, considering a probable attrition rate of $10 \%$ [48], sample size was increased to 270 . As the number of nurses in the intensive care units, medical care wards, and surgical care wards in the study setting was almost the same, we selected ninety nurses from each of these wards to the study. Sampling was performed purposively. Eligibility criteria were work experience of more than 1 year in adult intensive care units or medical-surgical wards and recent use of PR for elderly people. Nurses who worked in other hospital wards (such as pediatric wards) and those who had managerial positions (such as head nurses) were not included in the study. 


\section{Data collection}

Data collection instruments were a demographic questionnaire (with items on gender, age, educational degree, work experience, and self-report history of receiving PRrelated educations at university or during professional practice) and the Perceptions of Restraint Use Questionnaire (PRUQ) (Additional file 1). PRUQ was developed by Evans and Strumpf in 1988 and was revised in 1993. As a self-report questionnaire, PRUQ is used to assess healthcare providers' perceptions about the relative importance of PR use for elderly people $[49,50]$. It has seventeen items which are scored on a five-point scale from 1 ("Not important") to 5 ("Very important"), resulting in a possible total score of 17-85 which also can be reported in the range of $1-5$. Higher scores show greater importance of PR use. Sharifi et al. [51] evaluated and confirmed the validity and the reliability of the Persian version of this questionnaire. Exploratory factor analysis in their study showed that the Persian PRUQ had three main dimensions, namely, "prevention of fall", "prevention of treatment discontinuation", and "creation of a safe environment". Confirmatory factor analysis also confirmed the appropriateness of this three-factor structure. Reliability assessment in that study also showed that the test-retest intraclass correlation coefficient, the Cronbach's alpha, and the construct reliability of the Persian PRUQ were 0.86 (95\% confidence interval: 0.74$0.93 ; P<0.001), 0.82$, and more than 0.7 , respectively. For data collection, participants were provided with the questionnaire and were asked to complete it at their earliest convenience. To minimize the frequency of the missing data, we provided participants with clear explanations about completing the questionnaire and answered their questions.

\section{Data analysis}

Data were analyzed using the SPSS software (v. 23.0). The measures of descriptive statistics as well as the independent-sample $t$ test, the one-way analysis of variance, and the multiple regression analysis were used to describe and analyze the data at a significance level of less than 0.05 . In regression analysis, numerical variables (such as age and work experience) were entered into the model at ratio level, while categorical variables (such as gender and educational degree) were entered at nominal and ordinal levels.

\section{Ethical considerations}

The Research Ethics Committee of the University of Social Welfare and Rehabilitation Sciences, Tehran, Iran, approved the study (IR.USWR.REC.1398.121). Nurses were informed about the study aim, confidentiality of their data, and voluntariness of participation, and then, written informed consent was obtained from all of them.

\section{Results}

In total, 270 nurses participated in the study. Response rate was $100 \%$ and there were no missing data. Most of them were female (78.5\%), had Bachelor's degree in nursing (58.52\%), and reported no history of receiving PR-related educations (88.5\%). The means of their age and work experience were $35.91 \pm 6.31$ and $8.87 \pm 5.48$ years, respectively.

The total mean score of PRUQ was $4.08 \pm 0.12$ in the possible range of $1-5$. It had significant relationship with participants' age, work experience, and history of receiving PR-related educations $(P<0.05)$, but had no significant relationship with their gender, educational degree, and affiliated hospital ward $(P>0.05$; Table 1$)$.

The multiple regression analysis through the Enter method was used to determine the predictors of the PRUQ score. Its results revealed that the significant predictors of the PRUQ score were age, work experience, and history of receiving PR-related educations. These three variables explained $82 \%$ of the total variance of the PRUQ score $(P<0.05$; Table 2$)$.

Participants' most important reasons for using PR were "Protecting an older person from falling out of bed", "Preventing an older person from pulling out a feeding tube", and "Preventing an older person from pulling out a catheter", respectively. The least important reasons were "Preventing an older person from taking things from others", "Keeping a confused older person from bothering others", and "Preventing an older person from wandering". The most important reasons for using PR in intensive care units were the same as medical wards and included "Protecting an older person from falling out of bed", "Preventing an older person from pulling out a feeding tube", and "Preventing an older person from pulling out a catheter", respectively. The most important reasons for using PR in surgical wards were "Preventing an older person from pulling out a feeding tube", "Protecting an older person from falling out of bed", and "Preventing an older person from pulling out a catheter", respectively. The total mean score of PRUQ among nurses in intensive care units was insignificantly greater than nurses in other hospital wards $(P=0.396)$. The only difference among nurses in different hospital wards was related to item 9, i.e. "Substituting for staff observation" $(P=0.001)$. The results of the Tukey's post hoc test indicated that the mean score of this item among nurses in intensive care units was significantly greater than nurses in medical and surgical wards $(P=0.001)$; however, there was no significant difference between nurses in medical and surgical wards respecting the mean score of this item $(P=0.992$; Table 3$)$.

\section{Discussion}

This study assessed nurses' perceptions about using PR for elderly people hospitalized in intensive care units 
Table 1 Participants' demographic characteristics and total mean score of PRUQ

\begin{tabular}{|c|c|c|c|}
\hline Characteristics & & N (\%) & PRUQ score (Mean \pm SD) \\
\hline Gender & $\begin{array}{l}\text { Female } \\
\text { Male } \\
\text { Test results }\end{array}$ & $\begin{array}{l}212(78.5) \\
58(21.5)\end{array}$ & $\begin{array}{l}4.09 \pm 0.12 \\
4.05 \pm 0.14 \\
t=-2.383, P=0.338\end{array}$ \\
\hline Age (Years) & $\begin{array}{l}20-29 \\
30-39 \\
\geq 40 \\
\text { Test results }^{\mathrm{b}}\end{array}$ & $\begin{array}{l}68(25.1) \\
116(43.0) \\
86(31.9)\end{array}$ & $\begin{array}{l}3.92 \pm 0.76 \\
4.07 \pm 0.48 \\
4.21 \pm 0.59 \\
F=451.410, P=0.001\end{array}$ \\
\hline Educational degree & $\begin{array}{l}\text { Bachelor's } \\
\text { Master's } \\
\text { Test results }^{\mathrm{a}}\end{array}$ & $\begin{array}{l}158(58.52) \\
112(41.48)\end{array}$ & $\begin{array}{l}4.09 \pm 0.12 \\
4.07 \pm 0.13 \\
t=-1.371, P=0.172\end{array}$ \\
\hline Work experience (Years) & $\begin{array}{l}1-5 \\
6-10 \\
>10 \\
\text { Test results }\end{array}$ & $\begin{array}{l}75(27.8) \\
114(42.2) \\
81(30.0)\end{array}$ & $\begin{array}{l}3.94 \pm 0.87 \\
4.08 \pm 0.55 \\
4.21 \pm 0.71 \\
F=29.677, P=0.001\end{array}$ \\
\hline History of receiving PR-related education & $\begin{array}{l}\text { Yes } \\
\text { No } \\
\text { Test results }\end{array}$ & $\begin{array}{l}31(11.5) \\
239(88.5)\end{array}$ & $\begin{array}{l}3.86 \pm 0.51 \\
4.11 \pm 0.89 \\
t=-13.562, P=0.001\end{array}$ \\
\hline Affiliated hospital ward & $\begin{array}{l}\text { Intensive care unit } \\
\text { Medical ward } \\
\text { Surgical ward } \\
\text { Test results }\end{array}$ & $\begin{array}{l}90(33.3) \\
90(33.3) \\
90(33.3)\end{array}$ & $\begin{array}{l}4.09 \pm 0.12 \\
4.06 \pm 0.13 \\
4.08 \pm 0.13 \\
F=0.929, P=0.396\end{array}$ \\
\hline
\end{tabular}

${ }^{\mathrm{a}}$ The results of the independent-sample $t$ test

${ }^{\mathrm{b}}$ The results of the one-way analysis of variance

and medical and surgical wards. The total mean score of PRUQ was $4.08 \pm 0.12$ (in the possible range of $1-5$ ), denoting that nurses considered PR use very important for care delivery to hospitalized elderly people. The high total score of PRUQ can also denote the wide use of PR $[41,43]$. Previous studies reported PR use as a simple and effective method for ensuring patient safety and preventing treatment discontinuation [3, 24, 39]. Yet, PR is considered as a dangerous intervention due to its physical, mental, and ethical complications and hence, should be used only in specific situations $[2,52,53]$. The total mean score of PRUQ in the present study was almost the same as the findings of a study in Turkey [2] which reported a score of 4.14, but was much larger than the scores reported in studies in Ireland [31] and the United States [42] which both were equal to 2.8. This discrepancy may be due to the different PR use guidelines and regulations used in different healthcare settings.
Evidence shows that effective PR-related legislations and periodical supervision of nurses' PR use can reduce their tendency for using PR $[3,4,31]$. There is no clear guideline for PR use in healthcare settings in Iran and hence, most nurses are unaware of appropriate PR use. On the other hand, nursing staff shortage in Iran makes nurses consider PR as an effective method for reducing their workload [40, 47]. Alleviating staff shortage, providing quality PR-related educations to nurses, and developing clear PR use guidelines are needed to reduce the inappropriate use of PR by nurses.

Study findings showed that nurses' most important reasons for using PR for hospitalized elderly people were to prevent them from falling out of bed and to prevent them from pulling out their feeding tubes and catheters. Several earlier studies also reported the same finding [2, $6,42]$. However, some studies showed that PR use does not necessarily reduce the risks of falling out of bed and

Table 2 The results of multiple regression analysis for predicting the total mean score of PRUQ based on demographic characteristics

\begin{tabular}{|c|c|c|c|c|c|}
\hline Predictors variable & B & SE & Beta & $t$ & $P$ \\
\hline Constant & 3.628 & 0.025 & - & 147.772 & 0.001 \\
\hline Gender & 0.004 & 0.008 & 0.013 & 0.502 & 0.616 \\
\hline Age & 0.101 & 0.012 & 0.612 & 8.692 & 0.001 \\
\hline Educational degree & 0.002 & 0.007 & 0.007 & 0.285 & 0.776 \\
\hline Work experience & 0.023 & 0.011 & 0.142 & 2.095 & 0.037 \\
\hline History of receiving PR-related education & 0.101 & 0.012 & 0.260 & 8.603 & 0.001 \\
\hline
\end{tabular}


Table 3 The total mean scores of PRUQ and its items according to participants' affiliated hospital ward

\begin{tabular}{|c|c|c|c|c|c|}
\hline PRUQ items & $\begin{array}{l}\text { Intensive care unit } \\
(\boldsymbol{N}=90) \\
\text { Mean } \pm \text { SD }\end{array}$ & $\begin{array}{l}\text { Medical ward } \\
(\boldsymbol{N}=90) \\
\text { Mean } \pm \text { SD }\end{array}$ & $\begin{array}{l}\text { Surgical ward } \\
(\boldsymbol{N}=90) \\
\text { Mean } \pm \text { SD }\end{array}$ & $\begin{array}{l}\text { Total } \\
(\boldsymbol{N}=270) \\
\text { Mean } \pm \text { SD }\end{array}$ & $\boldsymbol{P}$ value ${ }^{*}$ \\
\hline \multicolumn{6}{|l|}{ 1. Protecting an older person from: } \\
\hline a. Falling out of bed & $4.92 \pm 0.27$ & $4.86 \pm 0.34$ & $4.84 \pm 0.36$ & $4.88 \pm 0.33$ & 0.262 \\
\hline b. Falling out of a chair & $3.56 \pm 0.49$ & $3.46 \pm 0.50$ & $3.41 \pm 0.49$ & $3.48 \pm 0.50$ & 0.107 \\
\hline c. Unsafe ambulation & $4.61 \pm 0.49$ & $4.58 \pm 0.58$ & $4.56 \pm 0.58$ & $4.59 \pm 0.55$ & 0.864 \\
\hline 2. Preventing an older person from wandering & $2.87 \pm 0.33$ & $2.95 \pm 0.21$ & $2.89 \pm 0.32$ & $2.91 \pm 0.29$ & 0.151 \\
\hline 3. Preventing an older person from taking things from others & $2.58 \pm 0.50$ & $2.52 \pm 0.51$ & $2.66 \pm 0.47$ & $2.59 \pm 0.49$ & 0.140 \\
\hline $\begin{array}{l}\text { 4. Preventing an older person from getting into dangerous } \\
\text { places or supplies }\end{array}$ & $3.81 \pm 0.39$ & $3.84 \pm 0.36$ & $3.87 \pm 0.34$ & $3.84 \pm 0.37$ & 0.594 \\
\hline 5. Keeping a confused older person from bothering others & $2.90 \pm 0.32$ & $2.90 \pm 0.30$ & $2.88 \pm 0.32$ & $2.89 \pm 0.31$ & 0.963 \\
\hline \multicolumn{6}{|l|}{ 6. Preventing an older person from: } \\
\hline a. Pulling out a catheter & $4.89 \pm 0.32$ & $4.79 \pm 0.41$ & $4.81 \pm 0.39$ & $4.83 \pm 0.38$ & 0.174 \\
\hline b. Pulling out a feeding tube & $4.90 \pm 0.30$ & $4.82 \pm 0.38$ & $4.88 \pm 0.34$ & $4.87 \pm 0.34$ & 0.289 \\
\hline c. Pulling out an IV & $4.83 \pm 0.40$ & $4.73 \pm 0.65$ & $4.74 \pm 0.57$ & $4.77 \pm 0.55$ & 0.098 \\
\hline d. Breaking open sutures & $4.70 \pm 0.59$ & $4.54 \pm 0.65$ & $4.64 \pm 0.64$ & $4.63 \pm 0.66$ & 0.246 \\
\hline e. Removing a dressing & $4.63 \pm 0.58$ & $4.59 \pm 0.60$ & $4.61 \pm 0.58$ & $4.61 \pm 0.58$ & 0.882 \\
\hline 7. Providing quiet time or rest for an overactive older person & $3.51 \pm 0.50$ & $3.53 \pm 0.62$ & $3.56 \pm 0.56$ & $3.53 \pm 0.56$ & 0.802 \\
\hline 8. Providing for safety when judgment is impaired & $4.72 \pm 0.45$ & $4.57 \pm 0.58$ & $4.55 \pm 0.60$ & $4.61 \pm 0.55$ & 0.076 \\
\hline 9. Substituting for staff observation & $4.04 \pm 0.68$ & $4.42 \pm 0.56$ & $4.43 \pm 0.56$ & $4.31 \pm 0.62$ & 0.001 \\
\hline $\begin{array}{l}\text { 10. Protecting staff or other patients from physical } \\
\text { abusiveness/combativeness }\end{array}$ & $3.39 \pm 0.57$ & $3.53 \pm 0.54$ & $3.51 \pm 0.67$ & $3.47 \pm 0.60$ & 0.242 \\
\hline 11. Managing agitation & $4.70 \pm 0.46$ & $4.57 \pm 0.52$ & $4.55 \pm 0.49$ & $4.61 \pm 0.51$ & 0.094 \\
\hline Total PRUQ mean score & $4.09 \pm 0.12$ & $4.06 \pm 0.13$ & $4.08 \pm 0.13$ & $4.08 \pm 0.12$ & 0.396 \\
\hline
\end{tabular}

"The results of the one-way analysis of variance

accidental removal of catheters by patients [30, 43, 54]. Therefore, alternative methods should be used to reduce inappropriate use of PR. These methods include continuous patient monitoring, supporting and reassuring patients to reduce their anxiety, fulfilling their physical needs, increasing their mobility, involving their family members in the process of care delivery, improving environmental safety, using alarm systems, and covering catheters to make them invisible [20, 24, 26, 35, 55]. Some studies also recommended the early removal of catheters immediately after procedures and the limited use of invasive procedures in order to reduce the need for PR [17, 20, 30].

We also found that nurses with older age and greater work experience obtained significantly higher PRUQ scores. These findings are in line with the findings of two earlier studies $[2,56]$. Evidence shows that nurses' tendency for using invasive procedures during patient care increases with age and work experience probably due to the fact that they become more experienced and more courageous over time [57, 58]. Moreover, nurses' empathy with patients may reduce over time due to problems such as unresolved fatigue and job burnout [56], resulting in their progressive indifference to the pain and suffering associated with invasive procedures. The experiences and preferences of older nurses may affect younger nurses and increase their tendency for using PR. Therefore, periodical educations about appropriate PR use are needed, particularly for older nurses.

Study findings also revealed that nurses with the history of receiving PR-related educations obtained lower PRUQ scores. In other words, they attached lower importance to PR use. This finding implies that receiving quality educations about PR, its complications, and its alternatives can reduce its use by nurses. Several former studies also reported the same finding [24, 26, 53]. Moreover, we found that nurses' PRUQ score had no significant relationship with their educational degree. Contrarily, a former study reported that nursing assistants obtained higher PRUQ scores than registered nurses and attributed this finding to nursing assistants' lower information about the complications of PR use [24]. This difference between these two studies may be due to the fact that appropriate PR use is not adequately addressed in different nursing education programs in Iran. Two studies in Iran $[40,47]$ showed that nurses had limited knowledge about appropriate PR use and 
highlighted the necessity of providing quality PR-related educations at different levels of nursing education.

Our findings also indicated that while nurses in intensive care units obtained higher PRUQ scores than nurses in medical and surgical wards, this difference was not statistically significant. Previous studies $[2,6,30]$ reported the higher prevalence of PR use in intensive care units. Patients in intensive care units are critically-ill and are connected to different devices and systems. Therefore, they are more at risk for injuries and more likely to receive PR.

We also found that compared with nurses in intensive care units, their counterparts in medical and surgical wards assigned higher importance to the substitution of PR use for staff observation. This finding may be due to the limited number of beds in intensive care units for elderly patients in the study setting which resulted in their hospitalization in general hospital wards. Nurses in medical and surgical wards are more likely to substitute PR for staff observation due to low nurse-patient ratio and lack of patient monitoring systems in their wards.

\section{Limitations}

One of the study limitations was purposive sampling which limits the generalizability of the findings.

\section{Conclusion}

This study concludes that hospital nurses consider PR use as an important procedure for preventing patients from falling out of bed and removing catheters and tubes. The findings of the present study can be used as a guideline to provide nurses with in-service PR-related educations. Moreover, the findings highlight the need for improving staffing level, providing necessary equipment for using PR alternatives, and developing culturally-appropriate PR use guidelines and protocols.

\section{Supplementary information}

Supplementary information accompanies this paper at https://doi.org/10. 1186/s12877-020-01636-2.

Additional file 1. Data collection instruments. Perceptions of Restraint Use Questionnaire (PRUQ) and a demographic questionnaire.

\section{Abbreviations}

PR: Physical Restraint; PRUQ: Perceptions of Restraint Use Questionnaire; SPSS: Statistical Product and Service Solutions

\section{Acknowledgements}

We would like to thank the Research and Technology Administration of the University of Social Welfare and Rehabilitation Sciences, Tehran, Iran, for providing the necessary permissions for the study as well as the nurses who participated in the study.

\section{Authors' contributions}

All authors had significant roles in designing, conceiving, and conducting the study and drafting the manuscript. AS, NA, MFK, FMS, and AE contributed to designing the study. AS collected the data, and analyzed by
AE. NA, MFK, and FMS were the supervisor of the whole research and checked the data. The final report and article were written by AS and NA. All authors read and approved the final manuscript.

\section{Funding}

This study was part of a PhD dissertation in nursing approved and financially supported by the University of Social Welfare and Rehabilitation Sciences, Tehran, Iran (grant number: 982518). The funding body had no role in the design of the study and collection, analysis, and interpretation of data and in writing the manuscript.

\section{Availability of data and materials}

Data and material are available by the corresponding author on reasonable request. In order to access the raw data, it is necessary to obtain the permission of the University Research Vice-Chancellor.

\section{Ethics approval and consent to participate}

The study was approved by Research Ethics Committee of the University of Social Welfare and Rehabilitation Sciences (IR.USWR.REC.1398.121). Nurses were informed about the study aim, confidentiality of their data, and voluntariness of participation, and then, written informed consent was obtained from all of them.

\section{Consent for publication}

Not applicable.

\section{Competing interests}

The authors declared that they have no competing interests.

\section{Author details}

${ }^{1}$ Nursing Department, University of Social Welfare and Rehabilitation Sciences, Tehran, Iran. ${ }^{2}$ Nursing School, Baqiyatallah University of Medical Sciences, Tehran, Iran. ${ }^{3}$ Behavioral Sciences Research Center, Life Style Institute, Baqiyatallah University of Medical Sciences, Tehran, Iran.

Received: 11 March 2020 Accepted: 1 July 2020

Published online: 06 July 2020

\section{References}

1. Naderi S, Zaboli R, Khalesi N, Nasiripour AA. Factors affecting patient safety: a qualitative content analysis. Ethiop J Health Dev. 2019;33(2):73-80.

2. Karaka T, Aydin ozkan S, Derya ister E. Physical restraint use in elderly patients: perceptions of nurses in university hospitals. Turk Geriatr Derg. 2018:21(4):588-95

3. Goethals S, Casterlé BD, Gastmans C. Nurses' decision-making process in cases of physical restraint in acute elderly care: a qualitative study. Int J Nurs Stud. 2013;50(5):603-12.

4. Penelo E, Estévez-Guerra GJ, Fariña-López E. Validity and measurement invariance of the physical restraint use questionnaire (PRUQ) in nursing staff. J Clin Nurs. 2018;27(5-6):e1179-88.

5. Saarnio $R$, Isola A. Nursing staff perceptions of the use of physical restraint in institutional care of older people in Finland. J Clin Nurs. 2010;19(21-22): 3197-207.

6. Jiang $H, L i C, G u$ Y, He Y. Nurses' perceptions and practice of physical restraint in China. Nurs Ethics. 2015;22(6):652-60.

7. Agens JE. Chemical and physical restraint use in the older person. Br J Med Pract. 2010;3(1):302.

8. Springer $\mathrm{G}$. When and how to use restraints: learn about possible indications for restraint, types of restraints, and how to monitor patients in restraint. Am Nurse Today. 2015;10(1):26-7.

9. Korczak V, Kirby A, Gunja N. Chemical agents for the sedation of agitated patients in the ED: a systematic review. Am J Emerg Med. 2016;34:2426-31.

10. Miller RD, Stoelting RK. Basics of anesthesia. 5th ed. Philadelphia: Churchill. Livingstone; 2006.

11. Bleijlevens MH, Wagner LM, Capezuti E, Hamers JP, Workgroup IPR. Physical restraints: consensus of a research definition using a modified delphi technique. J Am Geriatr Soc. 2016;64(11):2307-10.

12. Barton-Gooden A, Dawkins PE, Bennett J. Physical restraint usage at a teaching hospital: a pilot study. Clin Nurs Res. 2015;24(1):73-90. 
13. Krüger $C$, Mayer $H$, Haastert $B$, Meyer $G$. Use of physical restraints in acute hospitals in Germany: a multi-centre cross-sectional study. Int J Nurs Stud. 2013;50(12):1599-606.

14. Eltaliawi AG, El-Shinawi M, Comer A, Hamazah S, Hirshon JM. Restraint use among selected hospitalized elderly patients in Cairo, Egypt. BMC Res Notes. 2017;10(1):633.

15. Langley G, Schmollgruber S, Egan A. Restraints in intensive care units-a mixed method study. Intensive Crit Care Nurs. 2011;27(2):67-75.

16. Park M, Tang JHC, Adams S, Titler MG. Evidence-based guideline: changing the practice of physical restraint use in acute care. J Gerontol Nurs. 2007; 33(2):9-16.

17. Said AA, Kautz DD. Reducing restraint use for older adults in acute care. Nursing. 2013;43(12):59-61.

18. Aseyedali M, Sadeghi-Mahalli N, Norouzi-Tabrizi K. A review on adult daycare centers in the world. Iran J Ageing. 2019;13(4):518-29.

19. Lim SC, Poon WH. Restraint use in the management of the ederly with dementia in hospital. Intern Med Res Open J. 2016;1(2):1-4

20. Cotter VT, Evans LK. Try this: avoiding restraints in hospitalized older adults with dementia. New York: Hartford Institute for Geriatric Nursing; 2018. Available from: https://consultgeri.org/try-this/dementia/issue-d1.pdf. Accessed 2 Jan 2019.

21. Dikiciyan J. Australian and New Zealand Society for geriatric medicine position statement abstract: physical restraint use in older people. Aust Ageing. 2016;35(3):225

22. Zencirci AD. Use of physical restraints in neurosurgery: guide for a good practice. In explicative cases of controversial issues in neurosurgery. 2012. Available from: http://www.intechopen.com/books/explicative-cases-ofcontroversial-issues-in neurosurgery/use-of-physical-restraints-in neurosurgery-guide-for-a-good-practice. Accessed 12 Sep 2019

23. Hazzard WR, Halter JB, Ousander JG, Studenski S, High KP, Asthana S, et al. Hazzard's geriatric medicine and gerontology. 7th ed. New York: McGrawHill Education Medical; 2017

24. Fariña-López E, Estévez-Guerra GJ, Polo-Luque ML, Pogrányivá AH, Penelo E. Physical restraint use with elderly patients: perceptions of nurses and nursing assistants in Spanish acute care hospitals. Nurs Res. 2018;67(1):55-9.

25. Chaves ES, Cooper RA, Collins DM, Karmarkar A, Cooper R. Review of the use of physical restraints and lap belts with wheelchair users. Assist Technol. 2007;19(2):94-107.

26. Möhler R, Nürnberger C, Abraham J, Köpke S, Meyer G. Interventions for preventing and reducing the use of physical restraints of older people in general hospital settings. Cochrane Database Syst Rev. 2016;2016(1212): CD012476.

27. Bai X, Kwok TCY, Ip IN, Woo J, Chui MYP, Ho FKY. Physical restraint use and older patients' length of hospital stay. Health Psychol Behav Med. 2014;2(1): 160-70.

28. Berzlanovich AM, Schopfer J, Keil W. Deaths due to physical restraint. Dtsch Arztebl Int. 2012;109(3):27-32.

29. Strout T. Perspectives on the experience of being physically restrained: an integrative review of the qualitative literature. Int J Ment Health Nurs. 2010; 19(6):416-27.

30. Rose L, Dale C, Smith OM, Burry L, Enright G, Fergusson D, et al. A mixedmethods systematic review protocol to examine the use of physical restraint with critically ill adults and strategies for minimizing their use. Syst Rev. 2016;5(1):194

31. Leahy-warren $P$, Varghese $V$, Day MR, Curtin M. Physical restraint: perceptions of nurse managers, registered nurses and health care assistants. Int Nurs Rev. 2018;65(3):327-35.

32. Luk E, Sneyers B, Rose L, Perreault MM, Williamson DR, Mehta S, Burry L. Predictors of physical restraint use in Canadian intensive care units. Crit Care. 2014;18(2):R46. https://doi.org/10.1186/cc13789.

33. Crutchfield P, Gibb TS, Redinger MJ, Ferman D, Livingstone J. The conditions for ethical application of restraints. Chest. 2019;155(3):617-25.

34. Muir-Cochrane E, Baird J, McCann T. Nurses' experiences of restraint and seclusion use in short-stay acute old age psychiatry inpatient units: a qualitative study. J Psychiatr Ment Health Nurs. 2015;22(2):109-15.

35. Hevener S, Rickabaugh B, Marsh T. Using a decision wheel to reduce use ofrestraints in a medical-surgical intensive care unit. Am J Crit Care. 2016; 25(6):479-86.

36. Lach HW, Leach KM, Butcher HK. Evidence-based practice guideline. Changing the practice of physical restraint use in acute care. J Gerontol Nurs. 2016;42(2):17-26.
37. Registered Nurses' Association of Ontario (RNAO). Delirium, dementia, and depression in older adults: assessment and care. 2nd ed. Toronto: Registered Nurses' Association of Ontario (RNAO); 2016. Available from: https://rnao.ca/sites/rnaoca/files/bpg/RNAO_Delirium_Dementia_ Depression_Older_Adults_Assessment_and_Care.pdf. Accessed 14 Aug 2019.

38. Guvercin $\mathrm{CH}$, Samur M, Gurkan K. The other side of the coin: nurses' views and behavior on physical restraint. Acta Bioethica. 2018;24(2):253-64.

39. Li X, Fawcett T. Clinical decision making on the use of physical restraint in intensive care units. Int J Nurs Sci. 2014;1(4):446-50.

40. Moradimajd P, Noghabi AA, Zolfaghari M, Mehran A. Physical restraint use in intensive care units. Iran J Crit Care Nurs. 2015;8(3):173-8.

41. Fariña-López E, Estévez-Guerra GJ, Gandoy-Crego M, Polo-Luque LM, Gómez-Cantorna C, Capezuti EA. Perception of spanish nursing staff on the use of physical restraints. J Nurs Scholarsh. 2014:46(5):322-30.

42. McCabe DE, Alvarez CD, MCNulty SR, Fitzpatrick JJ. Perceptions of physical restraints use in the elderly among registered nurses and nurse assistants in a single acute care hospital. Geriatr Nurs. 2011;32(1):39-45.

43. Aydin ozkan S, Karaka T, Ister E. Validity and reliability of the perceptions of restraint use questionnaire for use in Turkey. Turk Geriatr Derg. 2017;20(1): $30-7$

44. Kurata S, Ojima T. Knowledge, perceptions, and experiences of family caregivers and home care providers of physical restraint use with homedwelling elders: a cross-sectional study in Japan. BMC Geriatr. 2014:14(1):39.

45. Hofmann H, Schorro E, Haastert B, Meyer G. Use of physical restraints in nursing homes: a multicentre cross-sectional study. BMC Geriatr. 2015;15(1): 129.

46. Mohler R, Meyer G. Attitudes of nurses towards the use of physical restraints in geriatric care: a systematic review of qualitative and quantitative studies. Int J Nurs Stud. 2014;51(2):274-88.

47. Saeidi S, Khatiban M, Khazaei A, Soltanian A, Rahimi-Bashar F. Assessment of intensive care unit nurses' knowledge, attitude, and practice of physical restraint use. Sci J Hamadan Nurs Midwifery Fac. 2015:23(3):40-9.

48. Ebadi A, Zarshenas L, Rakhshan M, Zareian A, Sharifnia H, Mojahedi M. Principles of scale development in health science. Tehran: Jame-e-negar; 2017.

49. Strumpf NE, Evans LK. Physical restraint of the hospitalized elderly. Nurs Res. 1988;37(3):132-7.

50. Evans LK, Strumpf NE. Frailty and physical restraint. In aging and musculoskeletal disorders. New York: Springer; 1993.

51. Sharifi A, Arsalani N, Fallahi-Khoshknab F, Mohammadi-Shahboulaghi F, Ebadi A. The psychometric properties of Persian version of the perceptions of physical restraint use questionnaire in the elderly. Salmand: Iranian Journal of Ageing. Forthcoming 2020. In press.

52. Chang $Y$, Yu H, Loh $E$, Chang $L$. The efficacy of an in-service education program designed to enhance the effectiveness of physical restraints. J Nurs Res. 2016;24(1):79-86.

53. Younis GA, Ahmed SE. Physical restraint and maintenance of critically ill patient's safety in intensive care unit: effect of clinical practice guidelines on nurse's practice and attitude. IOSR-JNHS. 2017:6(4):6-21.

54. Heinze C, Dassen T, Grittner U. Use of physical restraints in nursing homes and hospitals and related factors: a cross-sectional study. J Clin Nurs. 2012 21:1033-40

55. Lee H, Park M, Lee SH, Lee M, Go Y, Kim CG. Factors related to use of physical restraints for older adults with dementia in long-term care settings. J Korean Gerontol Nurs. 2019;21(2):125-34.

56. Maleho ME. The attitudesand opinions of intensive care nurses on the use of ohysical restraints: thesis for nursing in University of the Witwatersrand: Johannesburg; 2018.

57. Pretz J, Folse V. Nursing experience and preference for intuition in decision making. J Clin Nurs. 2011;20(19-20):2878-89.

58. Traynor M, Boland M, Buus N. Autonomy, evidence and intuition: nurses and decision-making. J Adv Nurs. 2010;66(7):1584-91.

\section{Publisher's Note}

Springer Nature remains neutral with regard to jurisdictional claims in published maps and institutional affiliations. 